\title{
Development of a standardized multi-sensors system for on-line atmospheric pollution monitoring
}

\author{
Zaher Al Barakeh ${ }^{1,2}$, Philippe Breuil ${ }^{1}$, Nathalie Redon ${ }^{2}$, Christophe Pijolat ${ }^{1}$, \\ Nadine Locoge ${ }^{2}$, Jean-Paul Viricelle'. \\ ${ }^{1}$ Centre SPIN, Ecole des Mines de Saint Etienne, F-42027, Saint Etienne, France. \\ ${ }^{2}$ Département Chimie et Environnement, Ecole des Mines de Douai, F-59508, Douai, France. \\ viricelle@emse.fr
}

\begin{abstract}
:
Air Pollution monitoring and measurement are done by the use of sampling techniques and analysis equipment often heavy, complex and expensive. Although these methods offer us a high measurement precision their use is in a disadvantage for quality oriented applications where simple information with low precision can be sufficient. The use of semiconductor gas sensors networks can provide the answer for a "low cost" system intended for such applications in air pollution detection fields. The main disadvantages of these sensors are their low reproducibility and low long-term stability. Three identical portable autonomous sensors arrays were built to classify different type of encountered atmospheric pollution like urban, photochemical, or traffic pollution. A calibration procedure was established to correct any sensors drift. A standardization test was developed in order to standardize all sensors sensitivity. Complementary tests under low gas concentrations were made to prove the ability of such system to detect sub-ppm gas concentration. The obtained system was used for on-site pollution monitoring in association with the air quality monitoring networks in France (AASQA).
\end{abstract}

Key words: Air pollution detection, semi-conductor gas sensors, sensors array, gauging and standardization test, Fuzzy logic.

\section{Introduction}

Atmospheric pollution monitoring is usually done by a network of measuring stations. These stations are based on high performance industrial gas analyzers whom high price and heavy weight are one of the inconvenient of pollution monitoring [1]. Although these analyzers offer an excellent selectivity and precision towards targeted gases, their use could be problematic for some application where selectivity and precision are not a priority [2]. Recently, gas detection applications started using electronic gas sensors, especially semi-conductor ones, in simple gas detection fields [3]. Pollution detection with commercial gas sensors usually focused on identifying one single pollutant in the atmosphere [1] [4] or discriminating different pollutant gases in an artificial gas mixture [5]. We are intending to develop an autonomous portable system based on these sensors for real pollution classification.

\section{System development}

The system is formed by three identical sensors arrays each containing 9 sensors. To assure measurements autonomy, an electronic card was developed in order to register each array sensors responses on a SD card. In order to construct the best fitted system for pollution detection, gas species normally present in the atmosphere like regulated gases $\left(\mathrm{CO}, \mathrm{NO}_{2}\right.$ and $\mathrm{O}_{3}$ ), VOCs, and other non regulated gases that presence could indicate pollutions types like $\mathrm{CH}_{4}$ and $\mathrm{NH}_{3}$ should be easily detectable by this system. Therefore the sensors choice was naturally oriented to detect these gases. Chosen sensors are shown in table 1. In this table we can find the sensor type, its targeted gases as specified by the constructor and the detection range. It is clearly noticeable that these detection ranges are much higher than the usual pollutants concentrations in the atmosphere. Therefore testing these sensors under relatively low concentrations of gases was a necessity. We show in figure 1 sensors responses from one of the system arrays to low gas concentrations of 7 different pollutants. Measured variable for these sensors is their relative conductance variation:

$$
X_{R}=\frac{G-G_{0}}{G_{0}}
$$


With:

- $\quad \mathrm{X}_{\mathrm{R}}$ : relative conductance variation

- G: sensor's conductance

- $\mathrm{G}_{0}$ : reference conductance (base-line) calculated under reference gas.

\begin{tabular}{|c|c|c|}
\hline Sensor & Target gases & $\begin{array}{l}\text { Detection } \\
\text { range }\end{array}$ \\
\hline MICS5525 & $\mathrm{CO}$ & $1-1000 \mathrm{ppm}$ \\
\hline MICS2710 & $\mathrm{NO}_{2}$ & $0,5-5 \mathrm{ppm}$ \\
\hline MICS2611 & $\mathrm{O}_{3}$ & $0,1-1 \mathrm{ppm}$ \\
\hline TGS2600 & $\begin{array}{l}\text { Large specter of air } \\
\text { contaminants }\end{array}$ & $500-10000 \mathrm{ppm}$ \\
\hline TGS2602 & VOC-Odors- $\mathrm{H}_{2} \mathrm{~S}$ & $30-10000 \mathrm{ppm}$ \\
\hline TGS2611 & $\begin{array}{l}\text { Combustible gases - } \\
\text { Methane }\end{array}$ & $\begin{array}{l}500-10000 \\
\text { ppm }\end{array}$ \\
\hline TGS2620 & $\begin{array}{l}\text { Alcohol and solvent } \\
\text { vapors }\end{array}$ & $50-10000 \mathrm{ppm}$ \\
\hline MICS5521 & CO-VOC-Hydrocarbons & $0,1-100 \mathrm{ppm}$ \\
\hline MICS5914 & $\mathrm{NH}_{3}$ & $300-40000 \mathrm{ppm}$ \\
\hline
\end{tabular}

Table 1: Chosen gas sensors with their detectable gases and their specified detection range.

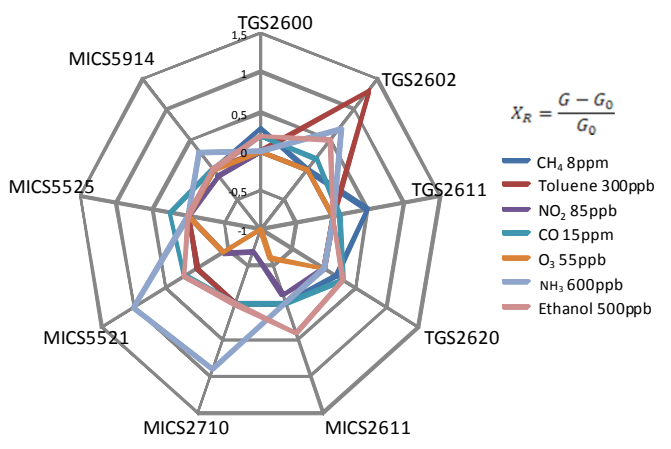

Figure 1: Sensors response for low concentration of pollutants

\section{Baseline drift correction}

Sensors baseline drift was studied by measuring and giving each month a reference conductance $\left(G_{0}\right)$ to each sensor calculated under reference gas (zero air) for specific conditions of temperature and relative humidity $\left(25^{\circ} \mathrm{C}, 50 \%\right)$. Figure 2 shows the evolution of sensors relative conductance $\left(G / G_{0}\right)$ for zero air flow during 7 months of tests.

Baseline drift value is specific to each sensor. Hence a periodic measurement of this change is necessary to ensure proper monitoring of the baseline. Therefore a gauging correction was done on a weekly basis to detect this drift in order to correct it, although it can probably be reduced to a monthly basis with no significant changes. It is imperative that this test is always repeated under the same conditions.

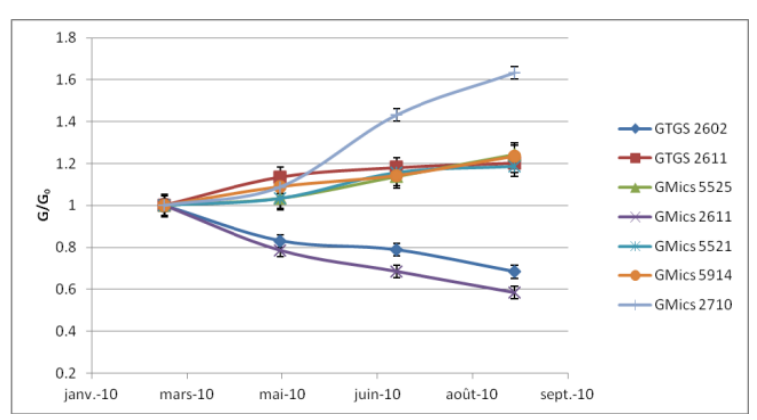

Figure 2: relative conductance under zero air variation during 7 months of measurements.

\section{Sensitivity change compensation}

Semi conductor gas sensiors tend to undergo changes in their sensitivity through time. Also same type sensors have different sensitivity to the same gases, hence the low response reproducibility. As a solution and to ensure the proper behavior, homogeneity between our arrays responses and relative repeatable and reproducible responses wie have elaborated a standardization test. Refierence gases were chosen (table 2). Each same type sensors responses will be standardized under one reference gas.

\begin{tabular}{|l|l|l|}
\hline Sensor & \multicolumn{2}{|c|}{ Reference gases } \\
\hline MICS5525 & $\mathrm{CO}$ & $20 \mathrm{ppm}$ \\
\hline MICS2710 & $\mathrm{NO}_{2}$ & $0.4 \mathrm{ppm}$ \\
\hline MICS2611 & $\mathrm{NO}_{2}$ & $0.4 \mathrm{ppm}$ \\
\hline TGS2600 & $\mathrm{NH}_{3}$ & $4 \mathrm{ppm}$ \\
\hline TGS2602 & $\mathrm{NH}_{3}$ & $4 \mathrm{ppm}$ \\
\hline TGS2620 & $\mathrm{NH}_{3}$ & $4 \mathrm{ppm}$ \\
\hline TGS2611 & Méthane & $20 \mathrm{ppm}$ \\
\hline MICS5521 & $\mathrm{CO}$ & $20 \mathrm{ppm}$ \\
\hline MICS5914 & $\mathrm{NH}_{3}$ & $4 \mathrm{ppm}$ \\
\hline
\end{tabular}

Table 2: Chosen reference gas and their accorded concentration for each sensor.

Standardization procedure was made by dividing the relative conductance variation of a sensor $X_{R-i, j}$ by its relative conductance variation for its targeted standardization gas $X_{\mathrm{s}-\mathrm{ij}}$ :

$\mathrm{S}_{\mathrm{i}, \mathrm{j}}=\mathrm{X}_{\mathrm{R}-\mathrm{i}, \mathrm{j}} / \mathrm{X}_{\mathrm{s}-\mathrm{ij}}$

This test was also periodically used as a diagnostic tool to detect any sensor failure that needs replacement. We show in figure 3 sensors response to standlardization gases and the effect of this sensitivity standardization on our sensors. We note the similarities between the responses after standardization. 


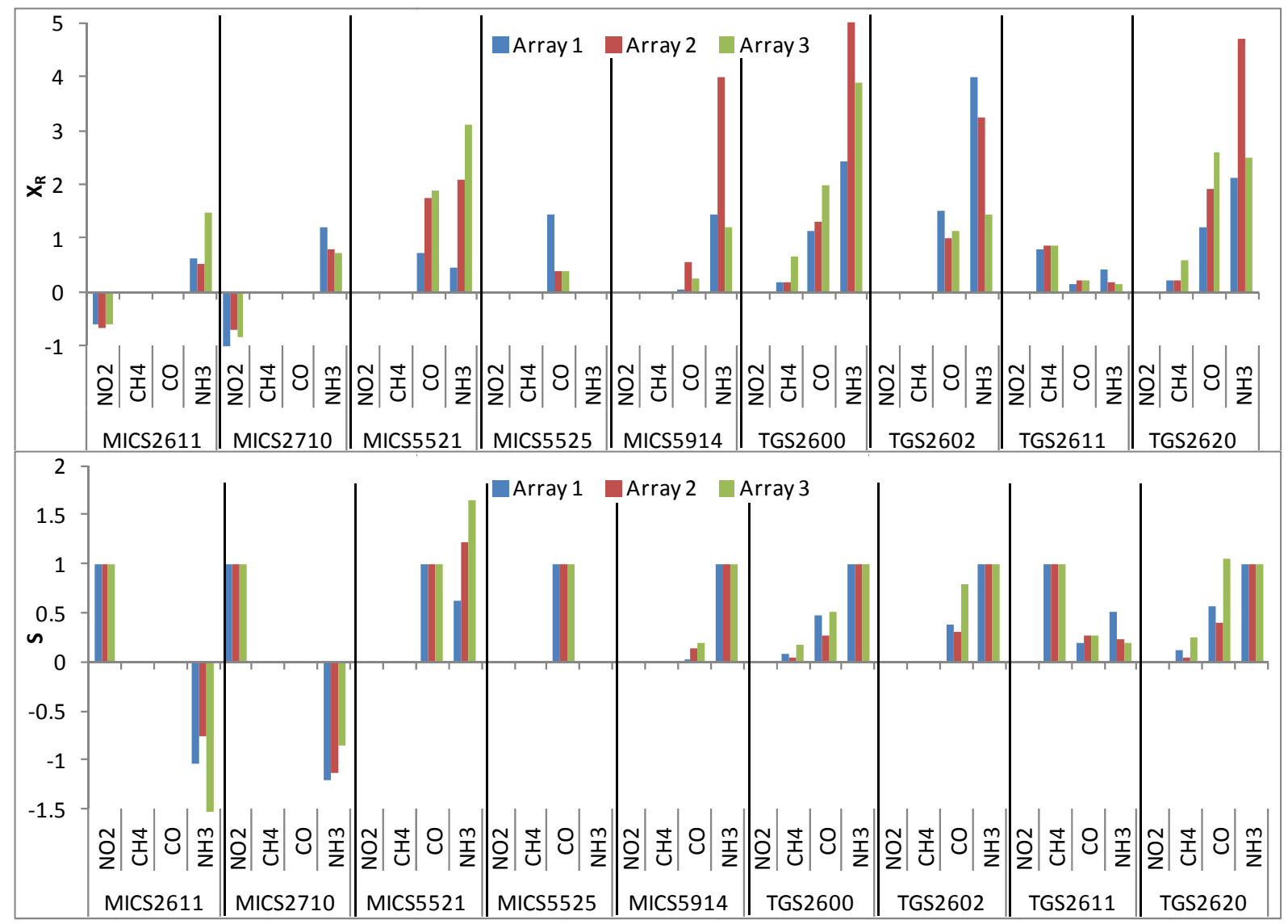

Figure 3: Sensors response to standardization test targeted gases: Sensors response before standardization (upper graph) and sensors response after standardization (lower graph).

\section{On site measurements}

After validating the system, we proceeded with 5 months of onsite pollution measurements. The system was installed inside different types of air quality monitoring stations in order to have synchronized sensors and analyzers pollution measurements.

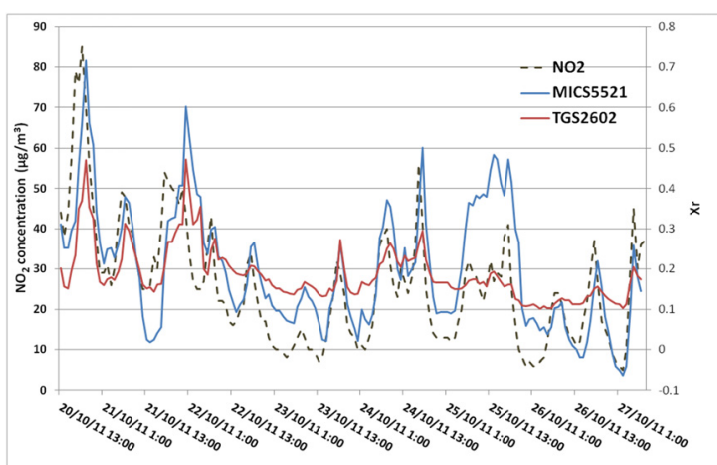

Figure 4: dotted line represents the $\mathrm{NO}_{2}$ evolution in the atmosphere, and the filled lines represent the relative conductance variation for two sensors.

During our measurements, we noticed that relative conductance variation of VOC sensors like TGS2602 and MICS5521 in traffic pollution spikes were correlated with $\mathrm{NO}_{2}$ concentration variation in the atmosphere like shown in figure
4. Although $\mathrm{NO}_{2}$ 's influence on these sensors should be a negative variation for being an oxidant gas, these sensors show a positive variation which can be only explained with the presence of non regulated gases originating from the same traffic source of $\mathrm{NO}_{2}$ hence correlated like alkanes in example.

A one year data history (2010) was collected from these stations and studied in order to define a credible pollution categorization according to its source. The analysis was oriented to find a repeatable patterns or specific characteristics that can define existing pollution in a station. Also repeated patterns in stations from similar types were studied. Four pollution categories were defined using a fuzzy logic approach by comparing $\mathrm{O}_{3}, \mathrm{NO}$, and $\mathrm{NO}_{2}$ concentration in the atmosphere (Photochemical, Traffic, Urban and Neutral pollution). Fuzzy logic was introduced in 1965 by Lotfi Zadeh [6] based on his mathematical theory of fuzzy sets. By introducing the notion of a degree of membership allowing a condition of being in a state other than true or false unlike Boolean logic, it provides flexibility and make it possible to take into account the inaccuracies and uncertainties. Hence a degree of membership is calculated for each category which can be used to classify the existing 
pollution; existing pollution is classified by the category that has the highest membership degree.

Artificial neural networks (ANN) models were developed to calculate the membership degree of each category out of standardized sensors responses for each array. A model was built for each measured site and for each array. Sensors responses were used as input and other additional variables were used as input too like the relative humidity's sensor response of each array, the hour of the day and information about work days. We show in figure 5 categories membership degrees for existing pollution during one day of measurement and the calculated membership degree from sensors responses during the same day.

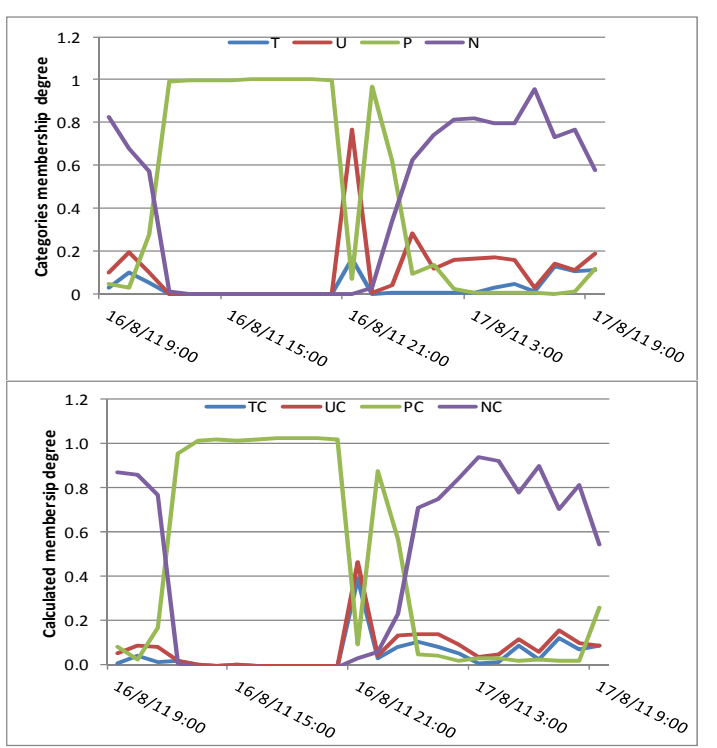

Figure 5: graphs showing categories membership degrees (upper graph) during a day of measurements, and calculated membership degrees out of sensors responses (lower graph).

The ratio of correct prediction and classification obtained out of calculated models for different sites was higher than $80 \%$ for tested and modeled data.

\section{Conclusion}

The concept of a qualitative pollution detection using a gas sensor array was presented in this work. The method is based on modeling temporal responses of semiconductor gas sensors in a sensor array. 3 identical sensors array were constructed. Gauging and standardization tests were elaborated to correct temporal signal drifts and assure an inter system homogeneity in sensors response. The study was carried out by measuring existing pollution in real life polluted sites. A neural network model was trained to predict pollution type from temporal sensors responses. Further results are being acquired and processed in order to verify the possibility of calculating more universal models to verify inter-cells and intersites model portability.

\section{References}

[1] Calibration of a multivariate gas sensing device for atmospheric pollution measurement. Kamionka M., Breuil P. and Pijolat C. 323-327, s.l.: Sensors and Actuators B, 2006, Vol. 118.

[2] New perspectives of gas sensor technology. Nobori, Y. et Kengo, S. 100-107, s.l.: Sensors and Actuators B: Chemical, 2009, Vol. 138.

[3] The use of sensor arrays for environmental monitoring: interests and limitations. Bourgeois, W., et al. 852-860, s.I. : The Royal Society of Chemistry, 2003, Vol. 5.

[4] Gas sensor network for air-pollution monitoring. W. Tsujita, A. Yoshino, $\mathrm{H}$. Ishida, T. Moriizumi. 2005, Sensors and Actuators B 110, pp. 304-311.

[5] Identification of pollutant gases and its concentrations with a multisensors array. Negri, R.M. et Reich, S. 172-178, s.l. : Sensors and Actuators B, 2001, Vol.

[6] Fuzzy sets. Zadeh, L.A. 1965. Information and Control 8 (3): 338-353. 